\title{
Implementação de políticas educacionais: elementos para o debate e contribuições para o campo
}

Paula Louzano*

Pâmela Félix Freitas**

Ariane Faria dos Santos***

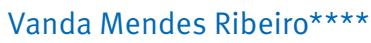

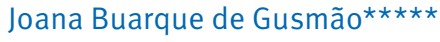

*(Faculdade de Educação, Resumo: Embora a produção acadêmica sobre Universidad Diego Portales, implementação de políticas públicas ainda seja incipiente, Santiago, Chile)

**(Centro de Estudos e Pesquisas em Educação, Cultura e Ação Comunitária - Cenpec, São Paulo, SP, Brasil)

***(Faculdade de Educação, Universidad Diego Portales, Santiago, Chile)

$\star \star \star \star$ (Universidade Cidade de São Paulo, São Paulo, SP, Brasil)

$\star \star \star \star \star$ (Centro de Estudos e Pesquisas em Educação, Cultura e Ação Comunitária - Cenpec, São Paulo, SP, Brasil) se comparada à literatura sobre agenda, formulação e avaliação, esta etapa é tida como central neste trabalho, dado seu importante papel no alcance dos resultados esperados. Este artigo busca sistematizar referências sobre implementação de políticas públicas em geral com destaque para o campo educacional. Para tanto, a temática da implementação de políticas públicas é, situada no campo, de acordo com a literatura, enfocando o papel dos diferentes agentes de implementação. Em seguida, alguns modelos de análises são descritos, com destaque para o modelo que Michael Fullan desenvolve para a análise de implementação de políticas educacionais. A revisão da literatura evidenciou a necessidade de ampliação de estudos sobre esta fase da política pública, em especial no campo educacional.

Palavras-chave: Políticas públicas. Políticas educacionais. Implementação de políticas. 
A produção acadêmica sobre implementação de políticas públicas é incipiente quando comparada à literatura acerca das demais fases de uma política, especialmente as que tratam do estabelecimento de agenda e formulação de políticas. Segundo Lotta (2008), a quantidade limitada de trabalhos sobre o assunto revela uma visão de que a fase de implementação seria pouco importante. Esse cenário não é diferente na área de implementação de políticas educacionais. Perez (2010, p. 1.182), ao problematizar especificamente a necessidade de pesquisar a implementação de políticas na educação, encontrou levantamentos (inclusive uma revisão de estudos em 19 países em desenvolvimento) que identificam um quase "descaso universal pelo tema da implementação". Sublinha-se, assim, a necessidade de ampliação de estudos sobre a fase da implementação das políticas públicas, em especial no campo educacional. Dessa forma, este artigo busca contribuir com o debate no Brasil, com especial atenção para o campo da educação.

Primeiro situaremos a temática da implementação no campo da política pública, enfocando a análise de como esta literatura tem tratado a questão e considerando o enfoque dado ao papel dos diferentes agentes de implementação. Em seguida, faremos um exame mais detido a respeito de um modelo de análise da implementação de políticas educacionais.

\section{A IMPLEMENTAÇÃO DE POLÍTICAS PÚBLICAS: LITERATURA GERAL}

Os estudos sobre políticas públicas são muito recentes se comparados às demais pesquisas em Ciência Política. As primeiras ideias foram desenvolvidas por autores como Laswell (1958), Lindblom (1959; 1979) e Easton (1965), que ficaram conhecidos como os "pais fundadores" da área ao criarem conceitos capazes de expressar como as ações dos governos podem agir sobre a sociedade. Mas, como área específica de conhecimento e disciplina acadêmica, as políticas públicas surgem apenas na década de 1960, com configurações diferentes na Europa e nos Estados Unidos:

\footnotetext{
[...] na Europa, a área de política pública vai surgir como um desdobramento dos trabalhos baseados em teorias explicativas sobre o papel do Estado - o governo - produtor, por excelência, de políticas públicas. Nos EUA, ao contrário, a área surge no mundo acadêmico sem estabelecer relações com as bases teóricas sobre o papel do Estado, passando direto para a ênfase nos estudos sobre a ação dos governos (SOUZA, 2006, p. 22).
}

Tal configuração contribuiu para que não se constituísse um consenso entre os pesquisadores a respeito do significado de política pública e do seu campo 
de atuação, estabelecendo uma distância entre aqueles que focam o papel do Estado e aqueles que se debruçaram sobre as ações dos governos. Os estudos sobre implementação de políticas públicas estão, em geral, vinculados à segunda abordagem.

Enquanto alguns autores definem a área de política pública como um campo dentro da política que analisa o governo à luz de grandes temas públicos (MEAD, 1995), outros afirmam que ela se constitui em um conjunto de ações do governo que produzirão efeitos específicos (LYNN, 1980). Há ainda pesquisadores que tentam conciliar tais visões ao afirmar que a política pública é a soma das atividades dos governos, que agem diretamente ou por meio de delegações, influenciando a vida dos cidadãos, e por isso tem um caráter público (PETERS, 1986). Segundo Souza (2006), a definição mais utilizada e conhecida ainda é a de Laswell (1958), que afirma que as análises sobre políticas públicas devem basicamente responder às seguintes questões: quem ganha o quê? Quando? Como? E que diferença isso faz?

Theodoulou e Cahn (1995) argumentam, por sua vez, que, em vez de olharmos individualmente para cada definição de política pública, é mais vantajoso compreender como as várias ideias e elementos presentes em cada um dos autores podem constituir um significado mais amplo para a área. Para isso, os autores identificam cinco elementos centrais das políticas públicas, a saber: (1) distinção entre planejamento (o que os governos planejam fazer) e a ação (o que, de fato, eles fazem), uma vez que a inatividade é tão importante quanto a própria atividade do governo; (2) importância dos agentes informais, pois a política pública não se restringe aos agentes formais; (3) abrangência da política pública, uma vez que ela vai além da legislação, decretos do executivo, regras e regulamentos; (4) intencionalidade da política pública, já que ela é um processo intencional de ação que tem como objetivo a realização de uma meta; (5) continuidade da política pública, pois ela envolve não apenas a decisão de promulgar uma lei, mas também as ações subsequentes de implementação, execução e avaliação (THEODOULOU; CAHN, 1995).

Os autores não só abordam os elementos essenciais presentes na política pública, mas também os enxergam como constituintes de um processo sistêmico, em que o todo é mais importante do que a soma das partes na obtenção de resultados. Além disso, ao afirmar que as políticas públicas não correspondem apenas ao processo de decisão, os autores apontam para a necessidade de compreender as particularidades de cada etapa da política na realização dos objetivos pretendidos. 
Embora as políticas públicas constituam processos contínuos e, muitas vezes, sobrepostos, a literatura costuma dividi-las em quatro etapas: i) agenda; ii) formulação; iii) implementação; e iv) avaliação. Enquanto a bibliografia sobre a agenda destaca os argumentos teóricos de como são construídos os assuntos que serão debatidos na esfera pública, a formulação se relaciona ao processo de como os governos traduzirão os propósitos em programas, projetos e ações que produzam resultados. Os escritos sobre a avaliação de políticas públicas costumam se dividir em duas correntes: a primeira busca analisar a política durante o seu desenvolvimento (monitoramento) e a segunda tem como objetivo analisar o resultado final da política (SOUZA, 2006). A implementação - objeto central deste trabalho - corresponde ao momento em que se busca compreender o que acontece com as ideias e objetivos quando os projetos são colocados em prática.

As pesquisas sobre implementação de políticas públicas têm sua origem na década de 1970, impulsionadas pela valorização dos governos nesse período, bem como pela crescente preocupação em compreender como as políticas públicas e as decisões governamentais impactariam a sociedade (BARRETT, 2004). O livro de Pressman e Wildavsky, lançado em 1973, pode ser considerado um marco da pesquisa, uma vez que nele os problemas com a implementação das políticas foram sistematizados pela primeira vez. Em seguida, vários trabalhos foram desenvolvidos com o intuito de investigar os motivos de as políticas públicas falharem ou mesmo não se concretizarem totalmente.

Matland (1995) divide os estudos sobre implementação de políticas públicas em três gerações. Para ele, os autores da primeira geração buscaram compreender como as decisões tomadas nos órgãos centrais eram implementadas (ou não), enquanto a segunda geração centrou suas pesquisas no papel dos agentes implementadores e na relação entre as políticas e as práticas. A terceira e última geração, ainda recente, vem tentando criar modelos teóricos de análise a partir dos estudos anteriores, buscando operacionalizar o conceito de implementação. A primeira geração de pesquisa teve início na década de 1970, a segunda situa-se na década de 1980 até o início da década de 1990; e a terceira vem produzindo seus trabalhos desde então (MATLAND, 1995 apud PAUDEL, 2009, p. 38).

O Quadro 1 procura sistematizar as principais características, contribuições e críticas de cada geração de pesquisa. Em seguida, cada uma delas será abordada em detalhe. 
Quadro 1 - As gerações de estudos sobre implementação de políticas públicas

1 a geração de estudos sobre implementação
Críticas




\section{3aㅡ geração de estudos sobre implementação}

\section{Características e contribuições}

- Tentativa de diferenciar os tipos de resultados ou padrões causais que ocorrem e a importância relativa de cada uma das variáveis independentes que fazem parte da análise.

- Busca criar um modelo teórico explícito que seja operacional.

- Busca por indicadores confiáveis de implementação e de previsão.

- Hipóteses derivadas de teorias, porém com análise de dados usando procedimentos estatísticos.

- Procura unir o mundo macro dos formuladores com o mundo micro dos implementadores.
Críticas

- Ainda é muito recente, porém já há críticas a respeito da pouca concretização prática de seus objetivos.

Fonte: Elaborado pelos autores.

Os primeiros estudos sobre a implementação apresentavam uma visão hierárquica do processo, ou seja, as decisões tomadas durante a fase de concepção da agenda e formulação da política eram as mais importantes, devendo ser apenas executadas pelos agentes de implementação. Essa perspectiva de análise, chamada por alguns autores de policy centred (HILL; HAM, 1993) ou implementação como controle (MAJONE; WILDAVSKY, 1995), postulava que a passagem da teoria à ação na política era algo natural, em que os implementadores estavam subordinados aos tomadores de decisão.

Nesse sentido, na primeira geração de estudos sobre implementação, a política era concebida a partir do estabelecimento de planos e objetivos, cuja adoção garantiria o sucesso da sua execução. Assim, esta visão não considerava que as políticas públicas poderiam sofrer adaptações e mudanças durante a fase de implementação, estando seu sucesso ou fracasso apenas subordinado à qualidade dos planos e metas traçados pelos formuladores da política. Porém, com o avanço da pesquisa sobre a implementação de diversas políticas públicas, observaram-se problemas durante essa fase que não dependiam necessariamente de uma formulação mal realizada, ou mesmo de planos e metas traçados de forma inconsistente. 
Autores como Pressman e Wildavsky (1973), Gun (1978), Sabatier e Mazmanian (1979) estudaram esses fatores e concluíram que: (1) a falta de clareza nos objetivos das políticas pode levar a interpretações diferentes na ação; (2) a grande quantidade e diversidade de atores envolvidos na implementação pode levar a problemas de coordenação e comunicação; (3) diferenças nos valores e interesses dos atores envolvidos pode resultar em maior ou menor motivação para implementação; e (4) a autonomia dos atores e agências na implementação pode dificultar o processo.

Como consequência dessas pesquisas, uma nova forma de enxergar a fase de implementação passou a ser valorizada: a implementação sob a perspectiva de negociação. Passou-se, assim, a considerar a barganha e a negociação entre atores semiautônomos que protegiam seus interesses como um fator determinante no processo de implementação (BARRETT; HILL, 1984 apud LOTTA, 2010). Surge assim a segunda geração de pesquisas em implementação.

Nesta segunda visão, a implementação é entendida como um processo dinâmico que vai além das decisões tomadas pelos formuladores ou por atores individuais. Surge uma nova agenda de pesquisa, que não se restringe às análises sobre os processos de tomada de decisão (LOTTA, 2008). Portanto, iniciaram-se estudos sobre o comportamento e as atividades desempenhadas pelos atores, pessoas e agências que estavam na linha de frente da implementação das políticas públicas. Esses agentes, que Lipsky (1980) denomina street level bureaucracy ou "burocracia do nível de rua", passaram a ser considerados fatores essenciais da implementação, uma vez que eles realizam (ou não) as atividades diretamente responsáveis pelo sucesso das políticas.

Mais especificamente, Hill (2003) postula que as pesquisas devem buscar compreender o entendimento que os implementadores têm sobre as políticas públicas e a forma de implementá-las. 0 autor aponta que o foco da literatura sobre implementação está, geralmente, na ação do governo, enquanto que aspectos relacionados às dinâmicas de implementação e à interação entre os sujeitos envolvidos nesse processo acabam sendo subestimados. Isso porque os implementadores são, em última instância, os responsáveis pela execução das políticas públicas e operam em condições políticas, institucionais e econômicas diversas que acabam influenciando diretamente a forma como as políticas são regidas. Além disso, eles carregam consigo concepções oriundas de sua trajetória, formação e experiência profissional, e contam sempre com alguma autonomia para decidir a forma de aplicá-las. 
Nesses estudos de segunda geração buscou-se entender também como o processo de implementação pode variar de acordo com a política e seus diferentes tipos de formato (centralizado ou descentralizado) e de acordo com a natureza das agências e áreas que a implementam. Dado que uma decisão tomada no nível central enfrentará percalços durante a sua operacionalização no nível local, passa a ser importante compreender as inter-relações entre os distintos níveis de governo e as políticas (PEREZ, 2010). Observou-se uma mudança importante na perspectiva da pesquisa, como enfatiza Lotta:

\section{[...] ao invés de questionarem se e como uma política tinha sido implementada ou comparando seus resultados com os seus pressupostos, os estudos de implementação começaram a observar o que acontecia na base, buscando identificar fatores que influenciavam a ação e o comportamento (LOTTA, 2008, p. 30).}

A segunda geração também buscou desenvolver modelos analíticos que pudessem ser utilizados para estudar a implementação de políticas (PAUDEL, 2009). A construção desses modelos e estratégias de pesquisa levou a duas abordagens distintas da implementação: os modelos top-down e bottom-up.

O modelo top-down mantém a divisão entre as estruturas responsáveis pela formulação da política e pelos agentes de implementação, focando o processo de colocar os programas e políticas em prática, buscando evitar que os agentes de implementação interfiram na concepção da política, de modo que planos e metas já traçados sejam, de fato, executados (LOTTA, 2010; HAM; HILL, 1973). Nessa perspectiva, as pesquisas tentam compreender como os processos e objetivos formulados são transformados de modo a buscar formas de traçar acordos para aumentar a coordenação das ações. Ham e Hill (1973) afirmam que um dos riscos desse modelo é que se controle excessivamente os agentes de implementação.

Por outro lado, a visão bottom-up concebe a política como um processo contínuo, em que as modificações e intervenções dos agentes fazem parte da consolidação da própria política. Nessa perspectiva, os resultados não dependem do cumprimento dos planos e propostas iniciais, mas sim do próprio processo de implementação. A política passa a ser flexível e adaptável, possibilitando diferentes decorrências (MAJONE; WILDAVSKY, 1995).

As variáveis e perspectivas relacionadas aos modelos top-down e bottom-up são apresentados no Quadro 2 e discutidas em seguida. 
Quadro 2- Diferenças entre top-down e bottom-up sob a pespectiva da implementação

\begin{tabular}{|c|c|c|}
\hline Variáveis & Perspectiva top-down & Perspectiva bottom-up \\
\hline $\begin{array}{c}\text { Tomador de decisões } \\
\text { políticas }\end{array}$ & Formuladores de políticas & $\begin{array}{l}\text { Burocratas de nível de } \\
\text { rua }\end{array}$ \\
\hline Ponto de partida & Linguagem estatutária & Problemas sociais \\
\hline Estrutura & Formal & Formal e informal \\
\hline Processo & Puramente administrativo & $\begin{array}{c}\text { Redes, incluindo as } \\
\text { administrativas }\end{array}$ \\
\hline Autoridade & Centralizada & Descentralizada \\
\hline $\begin{array}{l}\text { Produto ou } \\
\text { rendimento / } \\
\text { Resultados }\end{array}$ & Prescritivo & Descritivo \\
\hline Classificação & $\begin{array}{c}\text { Burocratas de nível } \\
\text { superior }\end{array}$ & $\begin{array}{c}\text { Burocratas de nível } \\
\text { inferior }\end{array}$ \\
\hline
\end{tabular}

Fonte: Paudel (2009, p. 40).

Hill (2003) postula que no modelo bottom-up a política pública passa a ser vista, necessariamente, relacionada à condição local, de modo que a tramitação e a execução das políticas ficam intrinsecamente ligadas a decisões coletivas e individuais de sujeitos ${ }^{1}$ e suas escolhas. Por isso, seria necessário focar as ações individuais e os pontos de partida de cada indivíduo (ou grupo) ao trabalhar com políticas públicas. Em outras palavras, essa perspectiva analítica está focalizada nos interesses individuais dos sujeitos contemplados ${ }^{2}$, de modo que muitas vezes as decisões tomadas por eles, incluindo a participação ou não em determinada política, devem ser influenciadas pelas origens e valores do sujeito. Já no modelo top-down, a implementação de uma política pública é vista como um processo racional e lógico, que segue um percurso relativamente linear desde o problema inicial até a avaliação final. Por essa razão, este modelo é acusado de desconsiderar possíveis conflitos entre metas ou mesmo entre percepções divergentes dos atores envolvidos, já que o peso maior é dado a soluções técnicas para os problemas da implementação da política. Ham e Hill (1973) afirmam haver também autores que, trabalhando sob a perspectiva top-down, consideram as aprendizagens trazidas pela abordagem bottom-up.

Por outro lado, o modelo bottom-up enxerga a implementação de políticas como uma atividade que considera os interesses dos atores individuais ${ }^{3} \mathrm{em}$

Termo usado pelo autor.

2 Tradução livre. Refere-se aos sujeitos que usufruem ou que são beneficiados pelas políticas.

3 O agente implementador das políticas é denominado de diferentes maneiras pelos 
todos os estágios da política. Se na fase de elaboração são definidas quais ações e alternativas são mais viáveis, envolvendo disputas, conflitos, acordos e negociações entre os atores políticos, é na fase de implementação que se colocam em prática os resultados desse conflito (PASSONE, 2012). Nessa visão, os conflitos de interesse e negociação, embora exprimam certa tensão, são aspectos importantes na implementação das políticas públicas. Os agentes implementadores reagem de diferentes formas às políticas prescritas, que podem, por isso, serem influenciadas, na fase de implementação, por vários fatores, tomando, inclusive, contornos diferentes dos iniciais. Para além da dinamicidade típica dos processos de implementação, há ainda que considerar a questão das interpretações a que a política formulada está sujeita, além das condições materiais e humanas para sua efetivação (SARAVIA, 2006).

Logo, a visão bottom-up entende que a implementação é um processo de interação e jogo entre os diversos agentes e fatores de implementação, cujo resultado se originará da dinâmica construída entre eles (BARDACH, 1977). Por esse motivo é que autores como Hjern e Porter (1993), Sabatier (1993) e Barrett e Fudge (1981) tentam identificar todos os agentes envolvidos no processo de implementação e traçar as interações que eles estabelecem entre si, a fim de melhor analisar a implementação das políticas. Isso porque, para essa linha de pesquisa, o mais importante na implementação de políticas seria compreender realmente como e por que as políticas são aceitas e implementadas em todos os níveis.

Para Lotta (2008, p. 5), a implementação passa a servista "como parte contínua e integral do processo político, envolvendo barganha e negociação entre os que querem colocar a política em ação e os de quem as ações dependem" e a define

\section{[...] pela interação entre atores no interior dos ambientes institucionais e relacionais presentes nas comunidades políticas. As dinâmicas políticas são resultado dessas interações, tendo em conta os constrangimentos das instituições e das redes de relações pessoais e institucionais presentes. Assim, o que temos como pressuposto é que as políticas são implementadas pela burocracia em interação, ou seja, não há mais apenas um agente responsável por todo o processo, mas um sistema (LOTTA, 2008, p. 5).}

Nessa visão, compartilhada por Arretche (2001), os agentes implementadores 4 são figuras pressionadas tanto pelas demandas de serviços para aumentar

autores utilizados.

4 Lotta (2008) refere-se aos agentes implementadores como burocratas-implementadores, enquanto Arretche (2001) usa apenas o termo implementadores ao se referir a esses atores. 
a efetividade quanto pelos cidadãos para aumentar a eficiência e a eficácia. Portanto, a implementação efetiva seria sempre realizada com base nas referências que os implementadores de fato adotam para desempenhar suas funções.

Por essa razão, Hill (2003) postula que a análise da implementação de uma política deveria considerar seu desenvolvimento prático como uma etapa importante, mais especificamente o exercício da discricionariedade por parte dos agentes implementadores, pois é no exercício da discricionariedade que esses agentes têm certa autonomia para decidir como aplicar ou implementar políticas públicas, podendo adaptá-las, alterá-las ou mesmo reconstruí-las.

Tal perspectiva traz à tona a necessidade de uma maior discussão acerca dos papéis desempenhados por diversos atores na implementação de políticas. Por essa razão, Lotta (2008) se propõe a analisar a implementação de política pública sob dois prismas: i) implementação como a interação entre os agentes envolvidos nos processos de execução da política, sejam eles burocratas ou não, buscando apreender as dinâmicas estabelecidas nas relações entre eles ao longo de uma cadeia de atividades, considerando que esses fatores impactam a construção das ações de implementação das políticas públicas; e ii) ampliação do olhar para os diversos valores e referenciais dos atores inseridos na implementação, considerando a influência desses fatores na execução das ações. Em suma, significa observar o ambiente institucional e relacional dentro do qual a burocracia opera, valores e preferências que, embora possam estar relacionados às trajetórias individuais, também são influenciados e moldados pelos treinamentos que recebem, pelas instituições por onde passaram e onde estão inseridos, pelas relações de poder estabelecidas no momento da implementação, entre outros.

Frey (2000) destaca que essas duas abordagens - top-down e bottom-up - se diferenciam no que tange à análise dos processos de implementação: a top-down analisa os aspectos normativos e regulatórios de uma política, tratando-se de uma investigação do conteúdo documental, enquanto a segunda (bottom-up) analisa o processo de implementação, destacando o "porquê" e o "como" dos resultados. Todavia, embora haja uma grande tendência atualmente de se aderir à visão bottom-up, Lotta (2010) pondera ser essencial compreendermos a implementação das políticas sob ambos os aspectos:

Por um lado, deve-se valorizar a ênfase que a visão top-down dá ao olhar para a política oficial, como a que molda a implementação ao definir a arena onde os processos se dão, as identidades e papéis dos principais atores e as ferramentas permitidas para adquirir e oferecer recursos [...]. Por outro lado, e complementarmente, deve-se olhar para os ajustes realizados nos programas, considerando o ambiente político, os processos de negociação e barganha e as formas de compromisso, típicos da visão bottom-up (LOTTA, 2010, p. 33). 
Entre os modelos de análise desenvolvidos pelos autores da segunda geração, destaca-se o de Matland (1995), que procura superar a dicotomia entre modelos top-down e bottom-up propondo uma classificação quanto à clareza de seus objetivos e o grau de incerteza de sua implementação. 0 Quadro 3 resume a visão e os exemplos utilizados pelo autor.

Quadro 3 - Tipos de implementação de política segundo Matland (1995)

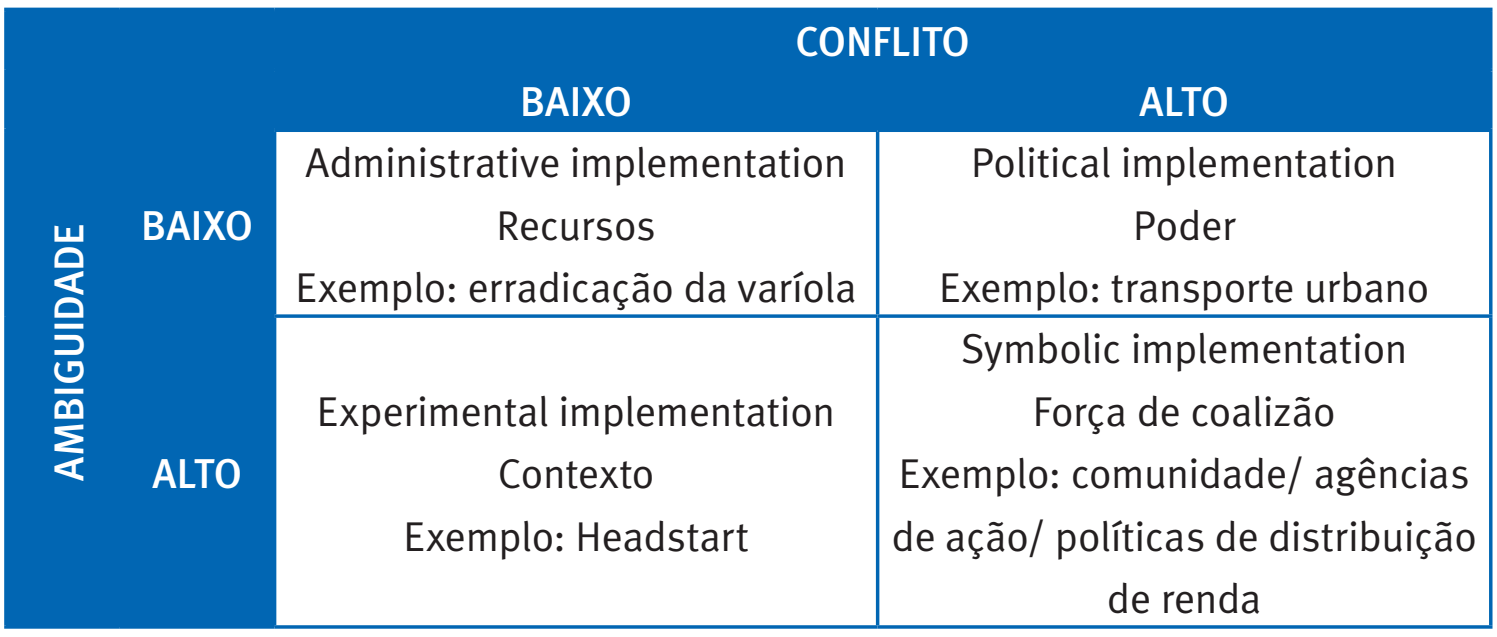

Fonte: Matland (1995, p. 60).

Segatto (2012) afirma que a partir do modelo de Matland, publicado em 1995, pode-se afirmar haver políticas que apresentam baixo grau de ambiguidade, quando a grande maioria da população concorda com sua implementação, por exemplo, e conta-se também com baixo conflito em sua implementação. Porém, há casos em que a ambiguidade de opiniões, por exemplo, é alta e a implementação também apresenta alto grau de conflito, como é o caso de políticas de distribuição de renda.

Para Segatto (2012, p. 8), essa classificação ajuda a integrar melhor a dicotomia entre implementações top-down e bottom-up:

A tipologia elaborada por Matland (1995) enriquece o debate sobre implementação, pois não contrapõe os modelos top-down e bottom-up, formuladores e implementadores, técnica e política.

Porém, embora Matland (1995) tenha conseguido conciliar tais visões, seu modelo esconde controvérsias importantes para a construção das políticas públicas, na avaliação de Hill (2006 apud SEGATTO, 2012): 
[...] a abordagem de Matland é, no entanto, um pouco estática e seu modelo de conflito inclui uma dicotomia muito simples. Muitas das mais controvertidas histórias de implementação (e talvez as mais interessantes) envolvem interações prolongadas em situações importantes e complexas de conflito entre múltiplas partes [...] (HILL, 2006, p. 77 apud SEGATTO, 2012, p. 7).

Viana (1996) apresenta o modelo de Grindle, de 1980, que, para ela, tenta lidar com esta questão ao colocar o maior peso dos empecilhos no processo de implementação em questões relativas ao contexto político das reformas. Nesse sentido, "os implementadores necessitariam de habilidade na arte da política e conhecimento do contexto político da implementação" (VIANA, 1996, p. 27). Com base na discussão acima, para demonstrar a complexidade das relações que devem ser levadas em consideração,

[...] a autora constrói dois modelos: o de escolhas críticas no processo de implementação e o de fases e condicionantes da implementação. No primeiro modelo, a autora ressalta as escolhas que são feitas na definição dos programas e políticas, as quais influenciam as estratégias de implementação. Na definição de estratégias de implementação, por sua vez, novamente são feitas escolhas que influenciam a liberação dos programas e políticas. Por último, quando se define quem será beneficiado pela implementação do programa ou política, mais uma vez são feitas escolhas quanto à alocação de recursos, com consequências para a sociedade e os indivíduos. Segundo a autora, essas escolhas estão condicionadas pelo contexto político-administrativo. No segundo modelo, que pretende sintetizar a fase da implementação, a autora relaciona conteúdos da política, contexto da implementação e resultados (VIANA, 1996, p. 27-28).

Este segundo modelo é demonstrado a seguir. 
Figura 1 - Modelo de Grindle (1980), segundo Viana (1996)

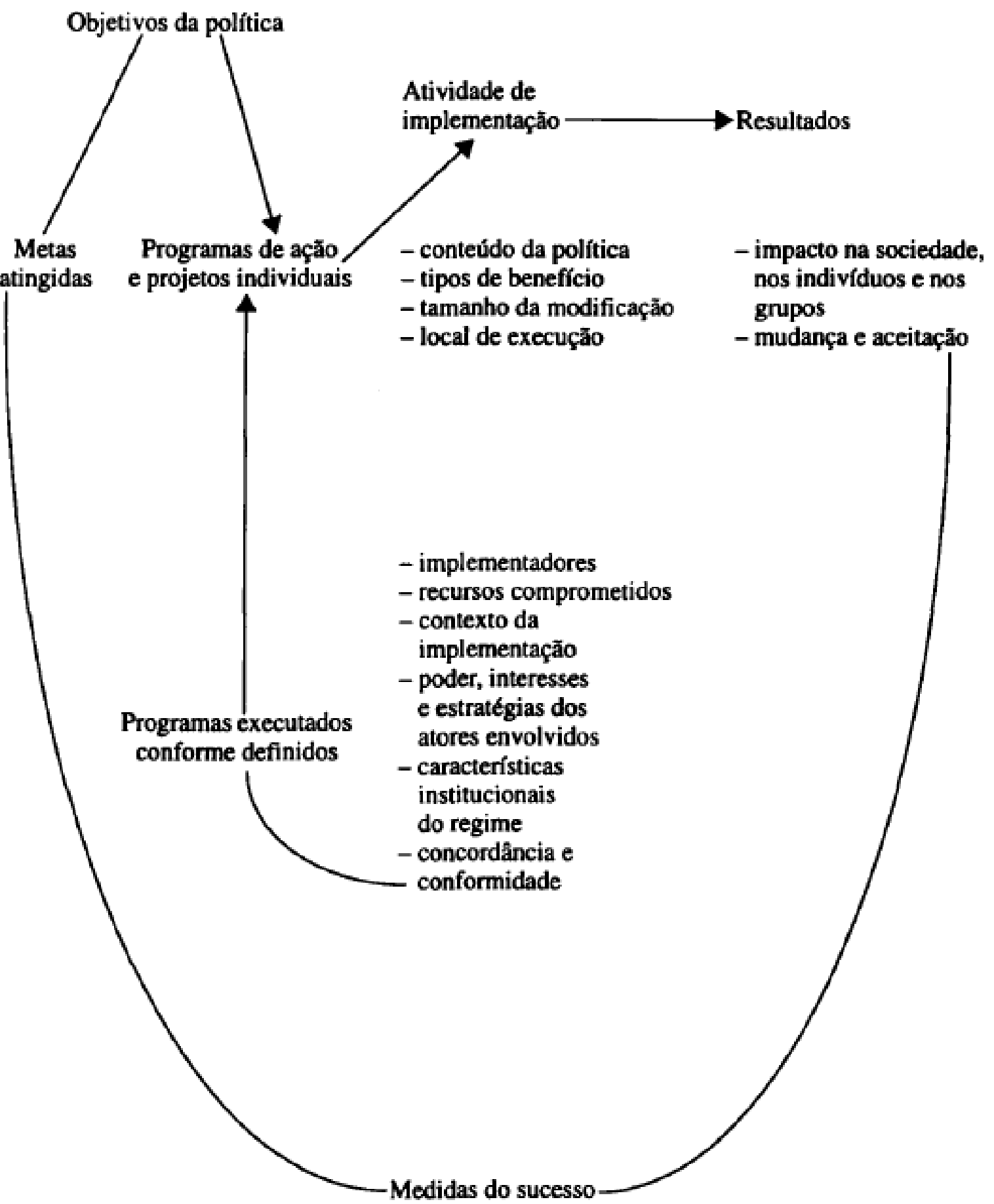

Fonte: Viana (1996, p. 28).

Finalmente, a terceira geração de pesquisadores da implementação tem buscado não só superar essa dicotomia entre modelos top-down e bottom-up, mas também especificar padrões que expliquem diferenças nos resultados de implementação, bem como determinar o peso de variáveis únicas para cada 
situação. No caso desses estudos, passa a ser importante circunscrever a análise da implementação a uma área específica da política pública, já que cada área apresenta suas especificidades, como é o caso da educação.

No entanto, estudos nessa linha ainda são incipientes, uma vez que terminam muitas vezes apresentando uma lista de variáveis que afetam a implementação e, portanto, não são capazes de oferecer uma teoria mais geral da implementação (PAUDEL, 2009). Na opinião desse autor, a terceira geração de pesquisas sobre implementação busca cobrir as lacunas presentes em áreas e questões específicas.

\section{AS PARTICULARIDADES DA IMPLEMENTAÇÃO DE POLÍTICAS EDUCACIONAIS}

No que tange à implementação de políticas educacionais, apesar de a bibliografia sobre implementação de políticas públicas levantar pontos muito importantes, ela não consegue tratar de todas as especificidades das políticas educacionais. Passone (2012, p. 2) afirma que, ao estudar qualquer fase de uma política educacional, é necessária a compreensão do tema a "partir da complexidade de relações que envolvem a política educacional, o seu contexto e seus atores”. Para Weber (2012), estudos que tratam das fases da política pública educacional têm, na maioria das vezes, que lidar com a dificuldade de que o pesquisador não participa do dia a dia da política, da sua implementação ou do seu monitoramento. Esse distanciamento atuaria, segundo a autora, como obstáculo à compreensão da complexidade que envolve esse fenômeno. Para ela, as políticas públicas não podem ser compreendidas fora de seu contexto.

Embora as pesquisas sobre implementação de políticas educacionais tenham começado simultaneamente às das demais áreas - por meio de análise de casos de como ocorreriam as implementações de políticas e projetos em escolas -, tais trabalhos só ganharam especificidade e destaque nos estudos sobre políticas educacionais a partir da década de 1970, quando as reformas pretendidas se tornaram mais complexas e, consequentemente, mais difíceis de ser implementadas. Como analisa McLaughlin (1998, 1975), quando as mudanças propostas pelas políticas passaram a exigir transformações nas ações e questões diretamente ligadas às escolas e às salas de aula, os estudos sobre implementação de políticas educacionais se intensificaram, a fim de entender as dificuldades que impediam a melhora na aprendizagem dos alunos e a diminuição das desigualdades entre os diferentes grupos. 
Assim, influenciados também pelas pesquisas sobre eficácia escolar, que cada vez mais demonstravam o papel essencial da escola e, principalmente, das práticas de sala de aula promovidas pelo professor, diversos autores vão procurar investigar o papel da implementação para se obter as mudanças que a terceira onda de reforma buscava. Nesse sentido, as pesquisas sobre implementação voltaram o seu olhar para o cotidiano da escola, o processo de planejamento e execução das aulas, a organização dos conteúdos e disciplinas, a capacidade de professores, diretores e coordenadores pedagógicos agirem conforme a reforma necessita, o engajamento em torno da aprendizagem, entre outros temas.

Dentre os diversos autores que analisaram a implementação de políticas nessa perspectiva (ADELMAN; PRINGLE, 1995; ANDERSON; SHIRLEY, 1995; BERENDS; KIRBY; NAFTEL; MCKELVEY, 2001; BERMAN; MCLAUGHLIN, 1975; 1978; COHEN, 1995; COHEN; BALL, 1990; COOK, 1991; COOPER; SLAVIN; MADDEN, 1998, DATNOW; CASTELLANO, 2000; FUHRMAN; ELMORE, 1990; FULLAN, 2009; KIRBY; BERENDS; NAFTEL, 2001; KNIGHT; STALLINGS, 1995), Michael Fullan se destaca. Ele, além de analisar a implementação de políticas educacionais, também buscou construir modelos de análise da implementação dessas políticas.

\section{O MOdelo de Michael FulLan}

Fullan (1985, 2009) destaca em seu modelo a importância de investigar o significado da mudança educacional tanto sobre o aspecto coletivo da política, ou seja, como ela modifica a sociedade como um todo - e não apenas a área educacional - quanto em relação ao significado subjetivo para os indivíduos envolvidos com a área da educação, já que estes serão os responsáveis diretos pelas ações que provocarão a mudança. Para isso, o autor busca compreender de maneira abrangente quais são os componentes do que ele denomina mudança educacional.

Compreender tais componentes torna-se ainda mais relevante na fase de implementação da política educacional na medida em que o sucesso dessa etapa depende justamente do entendimento e identificação dos elementos necessários para se colocar uma ideia, programa ou nova estrutura em prática. Sendo assim, 
A ideia da implementação e dos fatores que afetam o uso real parece simples, mas o conceito mostrou ser bastante complicado. Os exemplos de melhoras bem-sucedidas descritos na pesquisa dos últimos 30 anos parecem fazer sentido. Cada vez mais, as evidências apontam para um pequeno número de variáveis básicas, embora, como veremos, a questão do que

fazer permanece bastante complexa. Os dilemas intrínsecos ao processo de mudança, juntamente com a intratabilidade de alguns fatores, a singularidade de cada ambiente e as variações na capacidade local, tornam a mudança um processo social altamente complexo e sutil. As abordagens efetivas para lidar com a mudança exigem combinar e equilibrar fatores que aparentemente não andam juntos - simplicidade-complexidade simultâneas, frouxidãorigidez, liderança forte-participação dos usuários, estrutura de cima para baixo ou de baixo para cima, fidelidade-adaptabilidade e avaliação-falta de avaliação. Mais do que qualquer outra coisa, as estratégias efetivas para a melhora exigem um entendimento do processo, um modo de pensar que não pode ser compreendido em nenhuma lista de etapas ou fases a serem seguidas (FULLAN, 1985, p. 86).

Desse modo, Fullan (2009) percebe a mudança educacional como um processo dinâmico que envolve variáveis que interagem para desenvolver o sucesso ou o fracasso da política educacional. Por isso, ele constrói um modelo capaz de analisar os fatores críticos da implementação sem, contudo, reduzir sua complexidade. 0 autor parte do princípio de que os fatores que interferem na implementação das políticas educacionais podem ser divididos em três categorias: (i) características da mudança; (ii) características locais; e (iii) fatores externos. 0 modelo desenvolvido por Fullan (2009) pode ser resumido na Figura 2.

Figura 2 - Fatores interativos que afetam a implementação

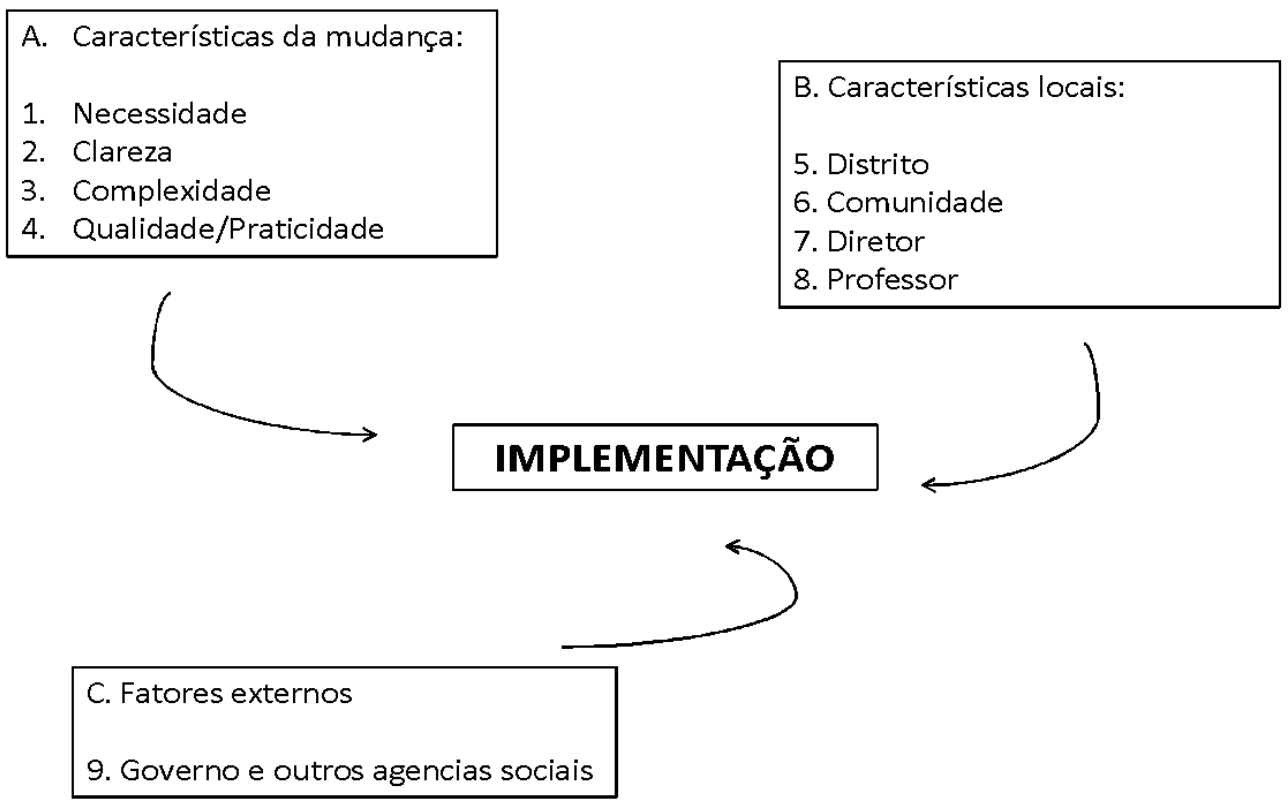

Fonte: Fullan (2009, p. 88). 
Com relação às características da mudança, o autor identifica e analisa quatro fatores essenciais para o sucesso da implementação: necessidade, clareza, complexidade e qualidade/praticidade. Tais elementos ajudam a levantar questões referentes às características das inovações propostas pelos programas e políticas educacionais, o que é muito importante para compreender as razões que muitas vezes impedem a perfeita implementação dessas ações.

Nesse sentido, prioridade é a palavra-chave para entender o que Fullan (2009, p. 88) quer dizer quando afirma que uma política de sucesso precisa ter necessidade. Por que muitas vezes uma política educacional é aprovada por apresentar um conjunto de ações interessantes e até mesmo relevantes para futuras conquistas educacionais, porém nem sempre esse programa atende aos desejos e necessidades mais urgentes e prioritários daqueles que devem implementá-la, sendo então parcialmente ou mal implementada, já que os esforços estarão direcionados para outra questão. Fullan (2009) discorre sobre as dificuldades de identificar as necessidades mais urgentes da comunidade e como isso se relaciona com a implementação.

\footnotetext{
Existem pelo menos três complicações. Primeiramente, as escolas enfrentam agendas de melhoria sobrecarregadas. Portanto, isso é questão não apenas de se dada necessidade é importante, mas também do quanto ela é relevante em relação a outras necessidades. $E$ desnecessário dizer que não é fácil fazer essa priorização entre conjuntos de necessidades, pois as pessoas relutam para abrir mão de seus objetivos, mesmo que não seja realista abordar todos eles. Em segundo lugar, as necessidades muitas vezes não são claras no começo, sobremaneira com mudanças complexas. As pessoas costumam entender as suas necessidades apenas quando começam a fazer coisas, ou seja, durante a implementação. Em terceiro lugar, a necessidade interage com os outros oito fatores para produzir padrões diferentes. Dependendo do padrão, a necessidade pode ser esclarecida ou ofuscada durante o processo de implementação (FULLAN, 2009, p. 89).
}

Desse modo, o autor nos mostra ser fundamental não apenas a identificação das necessidades prioritárias de um local, que nem sempre são nítidas à primeira vista, como a compreensão da interação deste fator com os demais. É por isso que cada fator, embora contenha uma face importante para a compreensão do problema, só ganha um sentido mais amplo em união com os demais.

Assim, à medida que cada fator complementa os demais a fim de integrar o sistema proposto por Fullan (2009), podemos afirmar que o segundo fator - a clareza - acaba sendo o caminho para realizar as necessidades educacionais levantadas pelo primeiro. Isso porque não basta apenas identificar a 
necessidade mais urgente se não se estabelecem formas claras de solucionar o problema. Nesse aspecto, o autor argumenta que é preciso ter clareza sobre os objetivos e meios do processo de mudança educacional, o que na prática significa identificar o que é preciso mudar e como realizar tais mudanças para atingir as necessidades da comunidade.

Porém, conseguir alcançar esse objetivo é mais difícil do que parece, pois muitas vezes uma política ou ação é adotada sem que as pessoas que irão implementá-la percebam realmente a mudança que ela deseja obter. Fullan (2009, p. 90) cita o caso de uma política de diretrizes curriculares no Canadá que foi rejeitada pelos professores porque eles diziam que já "estávamos fazendo isso", enquanto na verdade só enxergaram os objetivos superficiais e os aspectos temáticos da diretriz, em vez das novas estratégias de ensino propostas pela política. Consequentemente, esse ponto permite ao autor argumentar por que as políticas cujos objetivos e conteúdos mais detalhados são mais bem-aceitas, já que esses programas "proporcionam direcionamento" aos professores que colocarão a política em prática.

Por tais razões, após compreender a necessidade da comunidade, é preciso também desenhar os objetivos e meios da mudança a fim de que a política não seja mal implementada. Assim, como destaca Hargreaves (2003) faz-se necessário traçar caminhos para a mudança sem, contudo, ser prescritivo, pois isso nos impediria de enxergar as especificidades que podem aparecer apenas durante o processo de mudança.

Além do que, "a clareza também não é um fim em si: mudanças muito simples e insignificantes podem ser bastante claras, enquanto mudanças mais difíceis e importantes talvez não sejam facilmente compreendidas" (FULLAN, 2009, p. 90). Nesse sentido, a investigação da terceira característica da mudança educacional é essencial para avançarmos em nossa investigação: “a complexidade refere-se à dificuldade e ao nível de mudança exigido dos indivíduos responsáveis pela implementação” (FULLAN, 2009, p. 91, grifo nosso).

Como observa Fullan (2009, p. 91), toda mudança deve ser "analisada com relação à dificuldade, habilidade necessária e extensão das alterações em crenças, estratégias de ensino e no uso de materiais", pois serão esses elementos que ajudarão as pessoas responsáveis pela mudança a se preparar e traçar estratégias para sua perfeita implementação. E quanto mais sofisticada for uma mudança, mais difícil será sua realização, uma vez que exigirá esforços maiores e uma compreensão sobre aspectos mais específicos e essenciais da política. 
Todavia, mudanças complexas não devem ser desincentivadas apenas por serem difíceis, pois, como observaram Berman et al. (1977, p. 88), “projetos ambiciosos tiveram menos sucesso em termos absolutos da porcentagem de objetivos do projeto do que se esperava alcançar, mas geralmente estimularam mais mudanças nos professores do que os projetos que objetivavam menos". Para Fullan (2009, p. 91), a solução não é desistir das grandes mudanças, mas compreender que estas exigem mais esforço, clareza nos objetivos e meios, além de responsabilidade para manter as metas, até porque sua adoção terá consequências mais amplas.

Consequentemente, uma mudança educacional precisa ter ainda uma última característica para que sua implementação tenha sucesso: qualidade/ praticidade do programa/política. Isso significa que a decisão de adotar uma política deve vir acompanhada da preparação necessária para que a ação principal do programa possa ser realizada em plenitude. Para tal, não basta aprovar uma ideia, mas deve-se planejar o que será preciso para colocar essa ideia em prática, o que engloba tanto as questões materiais (estrutura física das escolas, material didático, transporte, etc.) quanto a formação das pessoas diretamente envolvidas com a implementação, que deverão compreender perfeitamente as intenções da política para poderem agir.

Desse modo, ao refletir sobre a qualidade que a implementação deve ter, é preciso atentar para erros que podem ser cometidos ainda na fase inicial de elaboração e aprovação da política. Muitas vezes um problema exige uma decisão tão rápida - seja por questões políticas, seja pela gravidade da situação - que não se pensa nos elementos e na preparação adequada para a realização da política.

Dito de outra forma, quando a adoção é mais importante que a implementação, as decisões muitas vezes são tomadas sem o tempo de preparação ou acompanhamento que é necessário para gerar materiais adequados. Os projetos ambiciosos quase sempre têm motivação política. Como resultado, a linha temporal entre a decisão de iniciar e o início propriamente dito geralmente é curta demais para atender os requisitos de qualidade (FULLAN, 2009, p. 92).

O modelo de Fullan (2009) não se resume em identificar as características do programa que propõe a mudança, uma vez que este também sofre influência dos fatores e agentes do ambiente no qual ele será colocado em prática. Por isso, Fullan (2009) inclui em sua análise as especificidades tanto dos fatores locais - o distrito escolar, a comunidade, o diretor e os professores que pertencem à região na qual a política será desenvolvida - quanto dos fatores externos - governo e demais instituições que possam afetar a política. 
Em relação aos fatores locais, é essencial olhar para "as condições sociais para a mudança, a organização ou o ambiente em que as pessoas trabalham e os eventos e as atividades, planejados e não planejados, que influenciam o fato de certas tentativas de mudança serem produtivas ou não" (FULLAN, 2009, p. 92-93). Para isso, não basta que apenas alguns dos agentes estejam propensos à mudança; se estes não encontrarem apoio nos demais, as transformações não serão duradoras. Pensando nesse aspecto, Fullan (2009) analisa cada um dos agentes responsáveis pela mudança no local e suas relações entre si, a fim de identificar pontos potenciais ou problemáticos à mudança.

O primeiro agente analisado é o distrito escolar, que no caso brasileiro se assemelha ao papel desempenhado pelas secretarias de educação ou diretorias de ensino. A respeito desse fator, a questão principal para Fullan (2009) está ligada ao histórico de tentativas de mudanças do local e como estas criaram, ou não, um ambiente propício às novas políticas.

A importância do histórico de tentativas de inovação no distrito pode ser colocada na forma de uma proposta: quanto mais experiências negativas os professores ou outras pessoas já tiveram com tentativas de implementação anteriores no distrito ou em outra parte, mais céticos ou apáticos eles serão para com a próxima mudança apresentada, independente dos méritos da nova ideia ou programa. Os distritos, províncias ou estados, e também os países, podem desenvolver uma incapacidade para a mudança, assim como capacidade para ela (FULLAN, 2009, p. 93).

Um segundo fator local para Fullan (2009) que muito pode influenciar a mudança são as características da comunidade escolar. Dependendo dos interesses e opiniões da comunidade na qual a escola está inserida, uma nova política pode ser rejeitada. Outro ponto desse mesmo dilema diz respeito às políticas que de alguma forma necessitam da participação e colaboração dos pais e da comunidade para que sua implementação seja um sucesso, por exemplo, os programas que buscam erradicar a evasão escolar.

Já em relação à dinâmica interna da escola, Fullan (2009) deixa bem clara a ideia de que a escola é a unidade ou o centro da mudança, o que demonstra quanto é essencial compreender a visão dos diretores e professores a respeito das novas políticas. Pois, na medida em que eles são os principais responsáveis pela efetivação de um novo programa dentro da escola, faz-se necessário levantar os problemas, desafios e potenciais com que esses agentes lidam para, inclusive, traçar formas de implementação que não estejam distantes da realidade da escola. 
Quanto ao papel dos diretores na implementação, Fullan (2009, p. 95) destaca um aspecto essencial de sua atuação: "as ações dos diretores servem para legitimar se uma mudança deve ser levada a sério e para amparar os professores do ponto de vista psicológico e logístico". Nesse sentido, devemos entender que o diretor é o agente responsável por abrir ou fechar a porta da mudança na escola, pois ao ser a pessoa capaz de entrelaçar as ações de todos os professores, pode criar caminhos para a implementação, assim como contribuir para que o professor tenha condições de também realizar a mudança.

O diretor é a pessoa mais provável de estar em posição de moldar as condições organizacionais necessárias para o sucesso, como o desenvolvimento de objetivos compartilhados, estruturas e climas de trabalho cooperativos, bem como procedimentos para monitorar os resultados (FULLAN, 2009, p. 95).

Por sua vez, os professores são os agentes nos quais a responsabilidade pela mudança educacional mais irá pesar, e justamente por isso é que compreender a pressão sofrida por estes seja tão importante para Fullan (2009) no processo de implementação de uma política. Além disso, diferente dos demais profissionais e instituições envolvidos na implementação, no caso dos professores, as características pessoais e psicológicas aparecem como uma questão fundamental para determinar em que medida este profissional estará disposto a aderir a uma mudança. Com base nesses pontos, diversos estudos têm demonstrado que a melhor forma de incentivar as mudanças nos professores é criando um ambiente de cooperação:

A mudança envolve aprender a fazer algo novo, e a interação é a principal base para a aprendizagem social. Novos significados, novos comportamentos, novas habilidades e novas crenças dependem muito de se os professores estão trabalhando como indivíduos isolados ou estão trocando ideias, apoio e sentimento positivos sobre o seu trabalho. A qualidade das relações de trabalho entre os professores está bastante relacionada com a implementação (FULLAN, 2009, p. 96).

Por último, mas não menos importante, Fullan (2009) afirma a necessidade de olharmos como os fatores externos à dinâmica escolar - como o governo, organizações não governamentais (ONGs), fundações de pesquisa e mesmo a sociedade de forma mais geral - podem exercer grande influência sobre a aceitação e implementação de algumas políticas. Pois não podemos esquecer que a maioria dos projetos e políticas é concebida para solucionar questões e necessidades que vêm da sociedade, do modo como esta pensa o seu sistema educacional. 


\section{CONSIDERAÇÕES FINAIS}

O levantamento realizado neste trabalho sinaliza questões relativas aos estudos sobre implementação de políticas públicas em geral e, em especial, as educacionais. A compreensão sobre a importância dessa fase da política pública tem quase 50 anos. 0 campo vem se desenvolvendo desde o início dos anos 1970, mas o significado de política pública e do seu campo de atuação não se constitui em um consenso entre os pesquisadores, estabelecendo muitas vezes uma distância entre aqueles que focam o papel do Estado e suas teorias e aqueles que se debruçaram sobre as ações dos governos para criar teorias explicativas.

A implementação de políticas públicas, como objeto central deste trabalho, busca compreender o que acontece com as ideias e objetivos no momento em que os projetos são colocados em prática. A implementação é, portanto, entendida pela literatura como um processo dinâmico quevai além das decisões tomadas pelos formuladores. É nessa fase que se expressam os conflitos, as disputas e as negociações presentes na fase anterior de elaboração. Por isso, não raramente, esta etapa compreende adaptações e mudanças em seu desenho inicial, pois os agentes implementadores reagem de diferentes formas às políticas prescritas, seja pelo elemento da discricionaridade, relativo a suas crenças e valores pessoais, seja pelas condições contextuais para sua execução.

Os estudos sobre implementação de políticas públicas podem ser divididos em três gerações. Os autores da primeira geração estavam interessados em compreender como as decisões tomadas nos órgãos centrais eram implementadas (ou não), enquanto a segunda geração centrou suas pesquisas no papel dos agentes implementadores e na relação entre as políticas e as práticas, gerando modelos analíticos mais complexos. A terceira e última geração, ainda recente, tem buscado especificar padrões que expliquem diferenças nos resultados de implementação, bem como determinar o peso de variáveis únicas para cada situação. No caso desses estudos, passa a ser importante circunscrever a análise da implementação a uma área específica da política pública, já que cada área apresenta suas especificidades, como é o caso da educação.

Um dos grandes desafios do estudo da implementação de políticas públicas educacionais está circunscrito na própria dificuldade de lidar com o fato de que o pesquisador não participa do dia a dia da política e, portanto, de sua 
implementação. Esse distanciamento, por si só, torna-se um obstáculo à compreensão da complexidade que envolve esse fenômeno, de acordo com alguns autores que estudam o assunto.

Dentre os autores que trabalham com implementação na educação, nos aprofundamos no modelo teórico de Michael Fullan. De acordo com seus estudos, ao mapear os fatores que interferem na implementação de políticas educacionais e que, portanto, se relacionam com esta área de atuação, um modelo de análise específico para a implementação dessas políticas pode ser construído. Para o autor, o primeiro agente analisado está nas secretarias de educação ou nas diretorias regionais de ensino. Já no âmbito da escola, considera essencial compreender a visão, os problemas e desafios que diretores e professores enfrentam na implementação das políticas, visto que eles são os principais responsáveis pela efetivação da ação dentro da unidade educacional.

Desse modo, a revisão da literatura deu relevo ao problema de que ainda há pouca produção acadêmica sobre a implementação, seja de políticas públicas, de modo geral, seja no tocante à educação. Trabalhos que abordam essas temáticas são ainda incipientes, especialmente quando comparados à literatura acerca das demais fases de uma política, como o estabelecimento de agenda, formulação e avaliação. Assim, espera-se que esta sistematização de estudos sobre implementação de políticas públicas e, em especial, de políticas públicas educacionais, possa fornecer uma contribuição para a consolidação deste campo de estudo. 


\section{Implementing educational policies: elements for debate and contributions to the field}

Abstract: While academic production on public policies implementation is still incipient when compared to literature on agenda, formulation and evaluation, this step is seen as crucial in this work, given its important role in reaching expected results. This article aims at systematizing references on public policies implementation in general, highlighting the educational field. Therefore, public policies implementation topic is situated in the field according to literature, with focus on the different implementation agents' role. Then, a few analyses models are described, highlighting the model developped by Michael Fullan for educational policies implementation analysis. Literature review showed the need of increasing studies about this step of public policy, especially in educational field.

Key words: Public policies. Educational policies. Policies implementation. 


\section{Implementación de políticas educacionales: elementos para el debate y contribuciones para el campo}

Resumen: Aunque la producción académica respecto a la implementación de políticas públicas sea todavía incipiente cuando comparada a la literatura sobre agenda, formulación y evaluación, esta etapa es considerada como central en este trabajo, debido a su importante papel en el establecimiento de los resultados esperados. Este artículo busca sistematizar referencias sobre implementación de políticas públicas en general con especial énfasis al campo educacional. Para eso, la temática de la implementación de políticas públicas es ubicada en el campo, de acuerdo a la literatura, enfocando el papel de los diferentes agentes de implementación. Luego, algunos modelos de análisis son descriptos, con especial atención al modelo que Michael Fullan desarrolla para el análisis de implementación de políticas educacionales. La revisión de la literatura hace patente la necesidad de ampliación de estudios sobre esta fase de la política pública, especialmente en el ámbito educacional.

Palabras-clave: Políticas públicas. Políticas educacionales. Implementación de políticas. 


\section{REFERÊNCIAS}

ADELMAN, N.; PRINGLE, B. Education reform and the uses of time. Phi Delta Kappan, v. 77, n. 1, p. 27-29, 1995.

ANDERSON, L. W.; SHIRLEY, J. R. High school principals and school reform: lessons learned from a statewide study of Project Re: Learning. Educational Administration Quarterly, v. 31, n. 3, p. 405-423, 1995.

ARRETCHE, M. Uma contribuição para fazermos avaliações menos ingênuas. In: MOREIRA, Maria Cecília Roxo; CARVALHO, Maria do Carmo Brant de. (org.). Tendências e perspectivas na avaliação de políticas e programas sociais. São Paulo: IEE/PUCSP, 2001.

BARDACH, E. The implementation game: what happens after a bill becomes a law. Cambridge, MA: MIT Press, 1977.

BARRETT, S. Implementation studies: time for a revival? Personal reflections on 20 years of implementation studies. Public Administration, v. 82, n. 2, p. 249-262, 2004. Disponível em: https://pdfs.semanticscholar.org/fa10/975cb 09e8ed27fe4c4ad842d44046dc29cb6.pdf. Acesso em: 24 de novembro de 2014.

BARRETT, S.; C. FUDGE (ed.). Policy and action. Londres: Methuen, 1981.

BERENDS, M.; KIRBY, S. N.; NAFTEL, S.; MCKELVEY, C. Implementation and performance in New American Schools: three years into scale-up. Santa Monica, CA: Rand, 2001.

BERMAN, P.; MCLAUGHLIN, M. W. Federal programs supporting educational change: the findings in review. Santa Monica, CA: Rand, 1975. (v. 4).

BERMAN, P. et al. Federal programs supporting educational changes: factors affecting implementation and continuation. Santa Monica, CA: Rand, 1977. (v. VII). Disponível em: https://www.rand.org/pubs/reports/R1589z7.html. Acesso em 15 de março de 2015.

BERMAN, P.; MCLAUGHLIN, M. W. Federal programs supporting educational change: implementing and sustaining innovations. Santa Monica, CA: Rand, 1978. (v. 8).

COHEN, D. K. What is the system in systemic reform? Educational Researcher, v. 24, n. 9, p. 11-17, 31, 1995. 
COHEN, D. K.; BALL, D. L. Policy and practice: an overview. Educational Evaluation and Policy Analysis, v. 12, n. 3, p. 347-353, 1990.

COOK, T. D. Clarifying the warrant for generalized causal inferences in quasiexperimentation. In: MCLAUGHLIN, M.; PHILLIPS, D. (ed.). Evaluation and education at quarter century. Chicago: National Society for the Study of Education. 1991. p. 115-144.

COOPER, R.; SLAVIN, R. E.; MADDEN, N. A. Success for all: improving the quality of implementation of whole-school change through the use of a national reform network. Education and Urban Society, v. 30, n. 3, p. 385-408, 1998.

DATNOW, A.; CASTELLANO, M. Teachers' responses to success for all: how beliefs, experiences, and adaptations shape implementation. American Educational Research Journal, v. 37, n. 3, p. 775-799, 2000.

EASTONE, D. A framework for political analysis. Englewood Cliffs: Prentice Hall, 1965.

FREY, K. Políticas públicas: um debate conceitual e reflexões referentes à prática da análise de políticas públicas no Brasil. Planejamento e Políticas Públicas, Brasília, n. 21, p. 211-259, jun. 2000. Disponível em: http://www. en.ipea.gov.br/ppp/index.php/PPP/article/viewFile/89/158. Acesso em: 20 jul. 2014.

FUHRMAN, S. H.; ELMORE, R. F. Understanding local control in the wake of state education reform. Educational Evaluation and Policy Analysis, v. 12, n. 1, p. 82-96, 1990.

FULLAN, M. Change process and strategies at the local level. The Elementary School Journal, v. 84, n. 3, p. 391-420, 1985.

FULLAN, M. O significado da mudança educacional. Tradução Ronaldo Cataldo Costa. Porto Alegre: Artmed, 2009.

GUN, L. A. Why is implementation so difficult?. Management Services in Government, v. 33, p. 169-76, 1978.

HARGREAVES, A. Teaching and the knowledge society. Nova York: Teachers College Press, 2003.

HILL, H. Understanding implementation: street-Level bureaucrats' resources for reform. Journal of Public Administration Research and Theory, v. 13, p. 265-282, 2003. 
HILL, M. Implementação: uma visão geral. In: SARAIVA, Enrique; FERRAREZI, Elizabete (Org.). Políticas públicas. Brasília: Escola Nacional de Administração Pública, 2006. p. 59-90.

HILL, M.; HAM, C. The policy process in the modern capitalist state. Nova York: Harvest, 1993.

HJERN, B.; PORTER, D. Implementation structures: a new unit of administrative analysis. In: HILL, M.; HAM, C. The policy process in the modern capitalist state. Nova York: Harvest, 1993.

KIRBY, S. N.; BERENDS, M.; NAFTEL, S. Implementation in a longitudinal sample of New American Schools: four years into scale-up. Santa Monica, CA: Rand, 2001.

KNIGHT, S.; STALLINGS, J. The implementation of the accelerated school model in an urban elementary school. In: ALLINGTON, R. L.; WALMSLEY, S. A. (ed.). No quick fix: rethinking literacy programs in American elementary schools. Nova York: Teachers College Press, 1995.

LASWELL, H. D. Politics: who gets what, when, how. Cleveland: Meridian Books, 1958.

LINDBLOM, Charles E. The science of muddling through. Public Administration Review, v. 19, p. 78-88, 1959.

LINDBLOM, Charles E. Still muddling, not yet through. Public Administration Review, v. 39, p. 517-526, 1979.

LIPSKY, M. Street-level bureaucracy: dilemmas of the individual in public service. Nova York: Russell Sage Foundation, 1980.

LOTTA, G. S. Agentes de implementação: um olhar para as políticas públicas. In: ENCONTRO DA ASSOCIAÇÃO BRASILEIRA DE CIÊNCIA POLÍTICA, 6., 2008, Campinas. Paper... Campinas, 2008.

LOTTA, G. S. Implementação de políticas públicas: o impacto dos fatores relacionais e organizacionais sobre a atuação dos burocratas de nível de rua no Programa Saúde da Família. 2010. Tese (Doutorado em Ciência Política) Universidade de São Paulo, São Paulo, 2010.

LYNN, L. E. Designing public policy: a casebook on the role of policy analysis. Santa Monica, CA: Goodyear, 1980. 
MAJONE, G.; WILDAVSKY, A. Implementation as Evolution. In: Theodoulou and Cahn. Public policy: the essential readings. Upper Saddle River, NJ, Prentice Hall, 1995.

MATLAND, R. E. Synthesizing the implementation literature: the ambiguityconflict model of policy implementation. Journal of Public Administration Research and Theory, v. 5, n. 2, p. 60, 1995.

MCLAUGHLIN, M. W. Macro and micro implementation. Santa Monica, CA: Rand, 1975.

MCLAUGHLIN, M. W. Listening and learning from the field: Tales of policy implementation and situated practice. In: International handbook of educational change. Springer Netherlands, p. 70-84, 1998.

MEAD, L. M. Public policy: vision, potential, limits. Policy Currents, n. 5, fev. 1995, p. 1-4, fev. 1995.

PASSONE, E. F. K. Fracasso na implementação de políticas educacionais: uma abordagem pelo discurso psicanalítico. 2012. 174p. Tese (Doutorado) - Faculdade de Educação, Universidade Estadual de Campinas, Campinas, 2012.

PAUDEL, N. R. A critical account of policy implementation theories: status and reconsideration. Nepalese Journal of Public Policy and Governance, v. 25, n. 2, p. 40, 2009.

PEREZ, J. R. R. Por que pesquisar implementação de políticas educacionais atualmente?. Educação e Sociedade, Campinas, v. 31, n. 113, p. 1179-1193, out./dez. 2010. Disponível em: http://www.cedes.unicamp.br. Acesso em: 20 de agosto de 2014.

PETERS, B. G. American public policy. Chatham, N.J.: Chatham House, 1986.

PRESSMAN, J. L.; WILDAVSKY, A. Implementation. Berkeley: University of California Press, 1973.

SABATIER, P.; MAZMANIAN, D. The conditions of effective implementation. Policy Analysis, v. 5, n. 4, p. 481-504, 1979.

SABATIER, P. Top-down and bottom-up approaches to implementation research. In: HILL, M.; HAM, C. The policy process in the modern capitalist state. Nova York: Harvest, 1993. 
SARAVIA, E. Introdução à teoria da política pública. In: SARAVIA, E.; FERAZEZI, E. (org.). Políticas públicas. Brasília: Enap, 2006. (v. 1, p. 21-43).

SEGATTO, C. I. Análise da implementação de políticas públicas: o Programa de Alfabetização na Idade Certa em dois municípios cearenses. Temas de Administração Pública, v. 4, n. 7, p. 1-16, 2012. Disponível em: https:// periodicos.fclar.unesp.br/temasadm/article/view/6189/4654. Acesso em: 24 de novembro de 2014.

SOUZA, C. Políticas públicas: uma revisão da literatura. Sociologias, n. 16, p. 20-45, 2006. Disponível em: http://www.scielo.br/pdf/soc/n16/a03n16.pdf. Acesso em: 24 de novembro de 2014.

THEODOULOU, S. Z.; CAHN, M. A. (ed.). Public policy: the essential readings. Englewood Cliffs, N.J.: Prentice Hall, 1995.

VIANA, Ana Luiza. Abordagens metodológicas em políticas públicas. Revista de Administração Pública, v. 30, n. 2, p. 5-43, 1996.

WEBER, S. Tônicas e questões abordadas nas duas últimas décadas nos textos sobre políticas educacionais publicadas na RBEP. Revista Brasileira de Estudos pedagógicos, v. 93, n. 234, 2012. Disponível em: http://rbep.inep. gov.br/index.php/RBEP/article/view/2682. Acesso em: 16 jun. 2014.

\section{SOBRE AS AUTORAS:}

Paula Louzano é doutora em Política Educacional pela Universidade de Harvard. Atualmente é Diretora da Faculdade de Educação da Universidade Diego Portales, em Santiago, Chile. E-mail: paula.louzano@udp.cl

Pâmela Félix Freitas é mestre e doutorando em Educação pela Faculdade de Educação da Universidade de São Paulo (FE-USP). Atua como pesquisadora da Diretoria de Pesquisa e Avaliação do Cenpec. E-mail: pamela.freitas@cenpec.org.br

Ariane Faria dos Santos é mestre em Educação pela Faculdade de Educação da Universidade de São Paulo (FE-USP). Atua como pesquisadora na Faculdade de Educação da Universidade Diego Portales em Santiago, Chile E-mail: ariane.faria@mail.udp.cl 
Vanda Mendes Ribeiro é doutora em Educação pela Faculdade de Educação da Universidade deSão Paulo (FE-USP) eprofessora do programa depós-graduação em Educação da Universidade Cidade de São Paulo (Unicid). Foi colaboradora da Coordenação de Desenvolvimento de Pesquisas do Cenpec entre 2013 e 2016. E-mail: vandaribeiro2@gmail.com

Joana Buarque de Gusmão é mestre em educação pela Faculdade de Educação da Universidade de São Paulo (FE-USP) e coordenadora de pesquisas do Cenpec. E-mail: joana.buarque@cenpec.org.br

Recebido em: março de 2019

Aprovado em: abril de 2019 